\title{
The gut microbiome
}

Editorial

Herb Brody, Richard Hodson,

Jenny Rooke

Art \& Design

Mohamed Ashour, Ffion Cleverley

Production

Nick Bruni, Karl Smart, lan Pope,

Kay Lewis

\section{Sponsorship}

Stephen Brown, Nada Nabil,

Claudia Danci

\section{Marketing}

Nicole Jackson

Project Manager

Rebecca Jones

Creative Director

Wojtek Urbanek

Publisher

Richard Hughes

VP, Editorial

Stephen Pincock

Managing Editor

David Payne

Magazine Editor

Helen Pearson

Editor-in-Chief

Magdalena Skipper
W e are not alone in our bodies. Living inside every person are trillions of microorganisms - bacteria, viruses, fungi and other life forms that are collectively known as the microbiome. Various organs have distinct microbial inhabitants, but the group that has attracted the most attention in biomedical research is the one in the gut.

To better grasp the part that gut microbes play in health and disease, researchers from around the globe are investigating what makes a 'good' gut microbiome (see page S6). There are, after all, hundreds of distinct bacterial species in the gut - some pathogenic and some beneficial. Computational biologist Eran Segal argues that collecting microbiome data would allow a 'deep phenotyping' approach that could transform drug discovery (S19). And the study of some health-promoting probiotic species is yielding biological insights that might promote drug development (S9).

Several diseases are now thought to be influenced by processes in the gut microbiome. Those include cancer (S16), autoimmune disorders such as multiple sclerosis (S12) and autism spectrum disorder (S14). The gut microbiome also strongly interacts with certain drugs, including some mental-health therapeutics, and influences their effects (S10).

With evidence mounting of the gut microbiome's health significance, synthetic biologists are looking to engineer the microbiome - both at the individual-species level and as an ecosystem - to thwart the development of disease (S20). There is also growing public interest in how the gut microbiome can be influenced - often focused on personal dietary choices. Microbiologist Peter Turnbaugh reframes this as a question not of which foods will benefit our health, but rather what medical insights might be gleaned from the interactions between our gut microbes and what we eat (S23).

Much more research is under way on the gut microbiome than can be covered in this Outlook, but this supplement gives a taste of the breadth of this robust field (S24).

We are pleased to acknowledge the financial support of Danone Nutricia Research in producing this Outlook. As always, Nature retains sole responsibility for all editorial content.

\section{Herb Brody}

Chief supplements editor available free online at go.nature. com/outlook

How to cite our supplements Articles should be cited as part of a supplement to Nature. For example: Nature Vol. XXX, No. XXXX Suppl., Sxx-Sxx (2020).

\section{Contact us}

feedback@nature.com

For information about supporting a future Nature Outlook supplement, visit go.nature.com/partner

Copyright ( 2020 Springer Nature Ltd. All rights reserved.

\section{Contents}

S6 ECOSYSTEMS

The hunt for a healthy microbiome

Understanding the ecosystem

S9 Q\&A

Homing in on the molecules from microbes

Michael Fischbach studies

short-chain fatty acids

S10 DRUGS

Gut reaction

The link with pharmaceuticals

S12 AUTOIMMUNE DISEASE

When immunity goes wrong

The microbiome and disease

S14 DEVELOPMENTAL DISORDERS Autism and the gut

Could there be a link?

\section{S16 CANCER}

Fighting cancer with microbes Boosting response to therapies

\section{S19 PERSPECTIVE}

Another dimension for drug discovery Microbiota data could transform therapy, says Eran Segal

\section{S2O SYNTHETIC BIOLOGY}

Engineering the microbiome Modifying microbes for therapy

S23 PERSPECTIVE

Use diet as a tool,

not a treatment

Scientists can't tell you what to eat, says Peter J. Turnbaugh

S24 CLINICAL TRIALS Research round-up Study highlights
On the cover

Scientists study the microbiome to work out its role in health and disease. Credit: Antoine Doré no influence on reporting there see go.nature.com/2NqAZ1d). A Nature Outlook supplements are 